\title{
Anxiety in the Youth Physical and Sport Activity
}

\author{
Raiola Gaetano \\ University of Naples Parthenope, Italy
}

Filippo Gomez Paloma

University of Salerno, Italy

Doi:10.5901/mjss.2015.v6n3s2p227

\author{
Altavilla Gaetano \\ University of Basilicata Potenza, Italy \\ raiolagaetano@libero.it
}

\section{Abstract}

The study tries to address and define whether the sport is stressful for young athletes. Anxiety and stress affecting both young people and adults, either team sports or individual although with different effects. What is the role of the coach in reading and management of emotional states of anxiety- based. Knowing the causes of anxiety allows us to understand how coaches can help their young athletes and make it bearable. The importance that the athlete learns to recognize and manage the anxiety to improve it to their advantage and finally, are some suggested tips to better manage anxiety competitive. Aim is to investigated on the phenomenon and establish some significant aspects and give relationships with the sport in physical education.

Keywords: Stress, performance, psychological implications, reading emotional states, emotional management of the competition.

\section{Introduction}

The agonistic activity seems more aimed at youth sporting success at any cost. In many places it is a cry of indignation against the operators of the sports industry, accusing them of distorting the growth of young athletes. This work tries to provide some indication of how the competitive sports activities both on a psychological stressful for the boys and how coaches can affect, positively or negatively, on the management of anxiety competitive and this have the influence on teaching method to acquire skills (Raiola G. 2014ab, Raiola et al 2014). The agonistic activity has a significant role in specific quickly skills as body language (Raiola 2012, Raiola et al 2012ab) and so on stress, such as in postural and balance (Raiola, Nughes, 2015). The amount of stress for a young athlete racing is a test that calls into question its investments both physical and psychological, social and economic resonance with an often high ; he can give a normal or pathological anxiety response to the competition (Ford et al, 2000). In a study by Simon and Martens (1979) compared the boys who were eager to practice seven different sports and not.

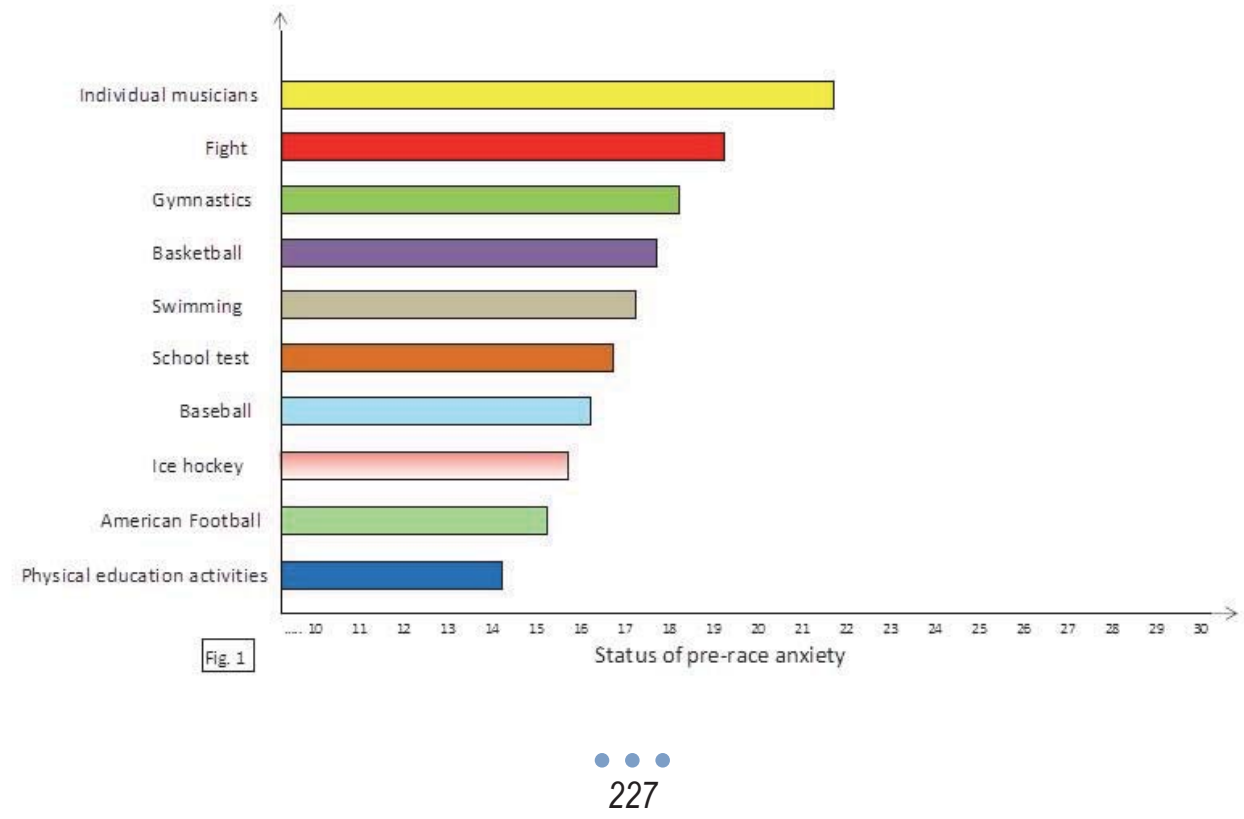


The importance that the athlete learns to recognize and manage the anxiety to exploit it to their advantage and finally, are some suggested tips to better manage anxiety competitive. Physical education lessons are the ideal context to study every aspects on the sport because the specific sample that are significantly of population (Di Tore et al 2012, Gaetano, 2012ab, Gaetano et al 2014). The aim is to investigated on the phenomenon and establish some significant aspects and give relationships with the sport in physical activity (Raiola, Tafuri, 2015).

\section{Method}

Taking reference in a search of Simon and Martens (1979) It was compared to the anxiety felt during the practice of these different sports with anxiety determined during a test at school, from participation in the physical education activities and during a musical performance. Simon used a psychological scale to detect different emotional states of the young performers at a precise moment of the performance.

\section{Results}

The results clearly indicate that they are not young athletes to have a high state of anxiety , but the soloist musicians. The sports activities that gives more anxiety are: fighting and gymnastics, both individual sports . Comparing , then , all team sports with individual ones we have seen that young athletes involved in individual sports were significantly more anxious than others. This has been demonstrated by other studies ( Flowers, Ross et al., 2002), or that athletes in individual competitions reported higher levels of anxiety compared to athletes who compete in team events .

\section{Discussion}

The percentage of children for whom the sport is too high stress is significantly lower ; in fact, it seems that the youth athletic activities cause more stress to the coaches that the athletes themselves. Although only a small percentage of kids are stressed out from competitive sports, it is important that coaches are able to identify the anxiety-inducing signals. It is fairly easy to recognize those athletes who show signs of anxiety and nervousness, such as nail biting, go to the bathroom systematically before each competitive event or show contract in the face. The reading of emotional states on the part of coaches is not always so simple. Often, in fact, they are so concerned about the preparation of the same by not capture these signals by their athletes. This inability may have practical implications ; because if the coaches are not able to grasp these were anxious of their young athletes certainly will not be even able to help them, in order to be able to obtain optimal levels of activation and motivation. Therefore the involvement is likely to be disorganized and accompanied by frustration, fear or depressed feelings (Yli-Piipari S. et al., 2009).

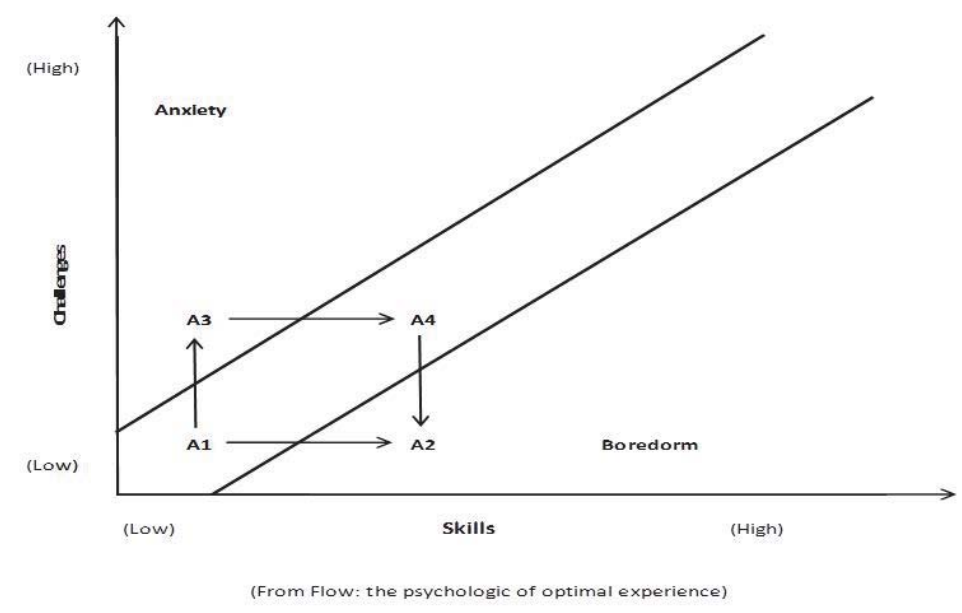

The challenge for the coach is to discriminate what could be the right level of activation for the player : to achieve and maintain it neither too high nor too low, before and during the game. The communication skills of the coach, affects very anxious about the state of the players : we must show calm, talk quietly, do not overemphasize the race, without 
forgetting the importance of the event. As expressed by the coach in the locker room, players will derive the forces to prepare for the race (Altavilla et al. 2014abc). The same happens during the game (eg in time-out of the basket)

The literature on this issue indicates that coaches should be educated to understand that train individuals and teams, and if they are able to identify the athlete anxious, you should know what to do to help him. It should first of all know the anxiety and stress, the causes of anxiety and competition strategies to contain it.

Anxiety is one of the most common psychological states experienced by individuals, which shows a state of agitation individual characterized by fear, nervousness, worry or panic. Stress, however, is a non-specific response activation shown when the body is faced with a need to adapt to new or unexpected disorganizing ; but stress can also assume a meaning unpleasant when it is produced in a way too intense and / or for long periods of time and / or is not accompanied by responses sufficiently effective .

We can distinguish two types of stress, one positive and one negative eustress called, distress called. Stress is correlated with individual characteristics of the athlete : for example, high anxiety on a competitive basis, associated with low self-esteem and poor intrinsic motivation can have a negative impact. Too intense and prolonged stress causes burn-out - a result not so much of stress, but that feeling of hopelessness (loss of hope) and be no way out (Lazarus , 1991).

The pre-game anxiety is influenced by many variables such as the context in which the sporting event is taking place , the subjective evaluation of the event and the personality of the athlete.

There are at least two causes that produce anxiety :

1 - The uncertainty of the outcome of the game

2 - The importance we attach to the outcome of the game

Young athletes do not feel able to be able to get a positive result in that situation more competitive and is attributed to the result of a given importance and the higher will be the state of anxiety. The coaches with his parents and classmates can make you feel young athletes insecure about their social status or in relation to their importance in the team.

A negative value judgment can lead to low self-esteem and increase anxiety, instead of receiving a positive judgment is psychologically strategic, not just for the account that will be of himself, but also to enhance its position within the group and compared to the other .

The best way to help our young athletes under stress is propose the objectives pursued and controllable to the competition. Is widely believed that the sport itself as the ultimate goal victory inevitable cause psychological repercussions more than any other factor. In fact, in any sporting competition the final victory depends on many factors, the behavior of all the teammates, the referees, the behavior and choices of the coach, but also by chance. And possible, therefore, to suggest the athletes to set itself objectives linked to the performance that can control and achieve. The presence of moderate levels of anxiety takes on a positive connotation because it creates motivation and mobility of personal energies, however if it reaches high levels it becomes blocker , preventing activate effectively all the resources at his disposal.

\section{Conclusions}

Overall, the majority of the literature finds that the experience of stress impairs efforts to be physically active (StultsKolehmainen M.A., Sinha R., 2014). Giving importance, above all, the mental and physical development and enjoyment of the children greatly increases the chances that they are not stressed, and anyway, they can better withstand stress. This depends very much on whether the family, coaches and fellow judge them positively independently by the results achieved. Instead, the boys who perceive their sporting successes also determine their value, they will risk affecting their performance every time you face a major athletic competition. Many coaches, and others, believe that most of the sporting successes depend on psychological factors. In fact, not infrequently happen to see the performance of teams or athletes technically very gifted and athletically, short of their potential. The performance of an athlete to optimize them , even from the perspective of cognitive - emotional, require the preparation of a program of psychological strategies in individual situation, with monitorable targets and achievable (Raiola 2015abc), taking into account the needs competitive individual and that it is a function of Scaleable course of training and competitions (Ntoumanis , 2001). Finally, it has now been shown that, if the sport is practiced without excesses and regularly, can prevent and relieve the symptoms of anxiety and stress ; because it helps to relax muscle tension and thus facilitates sleep. 


\section{References}

Altavilla, G.,Tafuri, D.,Raiola, G., 2014, Some aspects on teaching and learning by physical activity Sport Science vol 71 7-9

Altavilla, G., Raiola, G, 2014, Global vision to understand the game situations in modern basketball Journal of Physical Education and Sport Vol 14 issue 4, pp. $493-496$

Altavilla, G.,Afuri, D.,Raiola, G., 2014, Influence of sports on the control of static balance in physical education at school Journal of Physical Education and Sport Vol 143 pp. 351 - 354

Di Tore, P.A, Raiola, G., 2012 Case study on Physical Education and Sport in Naples Mediterranean Journal of Social Sciences, vol 311 479-484

Flowers H, Ross A. Brown, Chris H, 2002, Effects of sport context and birth order were on anxiety . Journal of Sport Behavior . Vol 25, pp.41 -56. University of South Alabama

Ford IW, Eklund RC , Gordon S., 2000 An examination of psychosocial variables moderating the relationship between life stress and injury time -loss Among athletes of a high standard . Journal of Sports Sciences. 18: 301-312

Gaetano, R. 2012a Didactics of volleyball into the educate program for coaches/trainers/technicians of Italian Federation of Volleyball (FIPAV) Journal of Physical Education and Sport vol. 122 25-29

Gaetano, R. 2012b Motor learning and didactics into physical education and sport documents in middle school-first cycle of education in Italy Journal of Physical Education and Sport vol. 122 157-163

Gaetano, R., Rago, V . 2014 Preliminary study on effects of hiit-high intensity intermittent training in youth soccer players Journal of Physical Education and Sport vol 142 148-150

Lazarus R. S., 1999 , Emotion \& Adaptation . Oxford University Press, New York

Ntoumanis N., 2001, Empirical links between achievement goal theory and self-determination theory in sport. Journal of Sports Sciences. 19: 397-409,.

Raiola G, 2015a, Basketball feint and non-verbal communication: empirical framework Journal of Human Sport and Exercise vol 101

Raiola G, 2015b, Sport skills and mental health, Journal of Human Sport and Exercise vol 101

Raiola G., 2015, Inclusion in sport dance and self perception, Sport Science, 81

Raiola G, Tafuri D. , 2015,Teaching method of physical education and sports by prescriptive or heuristic learning. Journal of Human Sport and Exercise vol 101

Raiola G, Nughes E, 2015, Postural control in young soccer players: differences between the cognitive approach and ecological-dynamic one, Journal of Human Sport and Exercise vol 101

Raiola, G., 2014a, Motor control and learning skills according to cognitive and ecological dynamic approach in a vision on behaviorism, cognitive, Gestalt and phenomenology theories Mediterranean Journal of Social Sciences vol 515 504-506

Raiola, G. 2014b Teaching method in young female team of volleyball Journal of Physical Education and Sport vol 141 74-78

Raiola, G., 2012, Bodily communication in volleyball between human and experimental sciences Mediterranean Journal of Social Sciences vol 3 587-597

Raiola, G.,Tafuri, D., Paloma, G., 2014, Physical activity and sport skills and its relation to mind theory on motor control Sport Science vol $7152-56$

Raiola, G., Di Tore, P.A 2012a Statistical study on bodily communication skills in volleyball to improve teaching methods Journal of Human Sport and Exercise vol. 72 468-488

Raiola, G., Di Tore, P.A. 2012b Bodily communication skills and its incidence on female volleyball championship to enhance didactics Journal of Human Sport and Exercise vol $71365-375$

Simon J. , Martens R., 1979, Children's anxiety in sport and sport no evaluative activities , Journal of sport psychology , 1, 160-169

Yli-Piipari S., Watt A., Jaakkola T., Liukkonen J. and Nurmi J., Relationships Between Physical Education Students' Motivational Profiles, Enjoyment, State Anxiety, and Self-Reported Physical Activity, Journal Sports Science \& Medicine 2009 Sep; 8(3): 327-336.

Stults-Kolehmainen M.A., Sinha R., The effects of stress on physical activity and exercise, Sports Med. 2014 Jan;44(1):81-121. doi: 10.1007/s40279-013-0090-5. US National Library of Medicine National Institutes of Health 